International Journal of Engineering \& Technology, $7(2.12)(2018) 244-247$
SPC

\title{
Power quality improvement of a PV and fuel cell connected microgrid
}

\author{
Saisrinivas. $P^{1} *$, Surya Kalavathi. $M^{2}$, Varunrohit. $\mathbf{V}^{1}$ \\ ${ }^{1}$ Dept. of EEE, M.V.G.R. college of Engineering, Vizianagaram, A.P., India \\ ${ }^{2}$ Professor EEE, JNTUCEH, Hyderabad, Telangana, India \\ *Corresponding author E-mail: patnanasai@gmail.com
}

\begin{abstract}
Increasing demands of $21^{\text {st }}$ century gain the need for sustainable energy. Non-conventional energy sources like solar, wind, fuel cell etc. are attaining much importance because of increasing environmental issues like Global Warming, Increase in Carbon foot prints etc. But, Non-conventional energy sources are not controllable. Hence, there is a need of sophisticated control of energies available to use them collectively. This can be made possible by the concept of Microgrid.

This paper presents the work done on a typical grid connected Microgrid, with Solar and Fuel cell as non-conventional energy sources, using MATLAB (Simulink). A variable irradiance is considered for PV array designed with an MPPT based on Perturb \& Observe Algorithm. A fuel cell stack with constant Hydrogen and air is considered. Here, the non-conventional energy sources are connected to Conventional grid. The variable DC obtained after Solar array is converted to three phase A.C by means of a three-phase inverter. The pulses for the inverter are generated by taking voltage and current both from grid side and PV side respectively as reference. Here, the control strategy to produce pulses for inverter is based on Phase locked loop (PLL) with a PI controller. One of the most important power quality indices like Total Harmonic Distortion (THD) is measured at various points and the power quality is improved by using a Cascaded LC filter.
\end{abstract}

Keywords: PV array; Fuel cell; MPPT; Total Harmonic Distortion; Phase Locked Loop.

\section{Introduction}

Energy is considered as the index of the economic growth \& development. In most of the developing countries like India, maximum energy requirements of the country are met through Thermal and Hydel Power Stations respectively. But thermal plants lead to pollution and Hydel are not sustainable. Basically, in the process of searching for an alternative to conventional energy and in the process of extending power to remote locations as well as rural areas in the developing countries majorly influenced by two factors such as cost associated in extension and maintainance of grid in those remote areas. The costs incurred in grid extensions heavily depends on various factors such as system type, connection length, topography, pattern being used and load factor of the supply point etc and varies widely with countries [1]. Hence, there is a requirement to rely on the power sources like solar, fuel cell, wind etc. to meet the goals. As of now Microgrid will be the most Fascinating solution for this.

A Micro-Grid can be defined as a distribution network which includes a group of DG sources, ESS (storage systems) and loads, operating as a single unit which can be controlled. These are capable of operating in Islanded or Grid connected modes. So, Micro grid is the one which is able to drive its own local loads even when it is disconnected from the main power grid. To maintain reliability these Micro grids are constructed at strategic points normally near load centres to the common grid. These micro sources are generally emerging with low capacity. Some of these are Fuel cells, Photo voltaic cells and some kind of wind turbines with power storage elements like Battery systems and Super capacitors etc. But these
Micro grids can cause some issues regarding Power quality, stability. Also, there is a necessity to maintain a sophisticated control over these networks to ensure protection and reliability.

Power Quality can be maintaining a near sinusoidal rated voltage at rated frequency. The power quality of any system can be quantified by means of power quality indices. In this paper the most important power quality index Total Harmonic Distortion is taken into consideration.

The organization of this paper is as follows. Section 1.2 deals with the concept of the photo voltaic energy, and its design considerations. Similarly, section 1.3 with fuel cell. Section 1.4 deals with the phase locked system for proper Synchronization of different micro sources and conventional grid. Section 1.5 deals with the design of filter to reduce the THD content in the system. Section 1.6 deals with the simulation results and finally Section 1.7 with the Conclusion of this paper.

\section{Photo voltaic system overview}

Photo Voltaic systems are gaining much importance because the Energy demanded by human in one year can be met easily in an hour from the energy delivered by the sun [1]. As per the expert's provisions, It would not be astonishing that by 2040 Energy obtained from PV system will reach $27 \%$ of world's overall energy consumed and will also become the most important non-conventional source of energy [2]. The term photo voltaic indicates the direct conversion of solar energy to electric energy. PV cells are made with different materials like silicon, gallium arsenide, cadmium tellurite and few other materials forming a p-n junction or a Schottky 
junction at the end of PV cell, to enable the photovoltaic effect. When the energy associated with photons of light is more compared to that of material used in pv leads to break of parent atom and creating free electrons. These electrons combineswith holes creating electron-hole pairs as shown in the Fig 1.1. As these electrons are very much unstable cause hole-electron pairs to exhaust as soon as they fall back into holes. Current due to electron is produced when an electric field is made available forcing the electrons to reach metallic contact moving away from holes in the conduction band. Thus, a depletion layer at the junction causing a p-n junction is created due to the applied electric field [1].

In pv cell in order to allow the flow of current the electrical terminals are placed at its top as well as bottom as shown in the Fig 1. The charge unbalance in the circuit due to light is reduced by connecting $\mathrm{p}$ and $\mathrm{n}$ type materials with the use of external circuit. Current starts to flow when the electrons passes through the load flowing from the $\mathrm{n}$ type electrode. These electrons when flow through p-side causes the recombination of electron-hole pairs and brings equilibrium to the system.

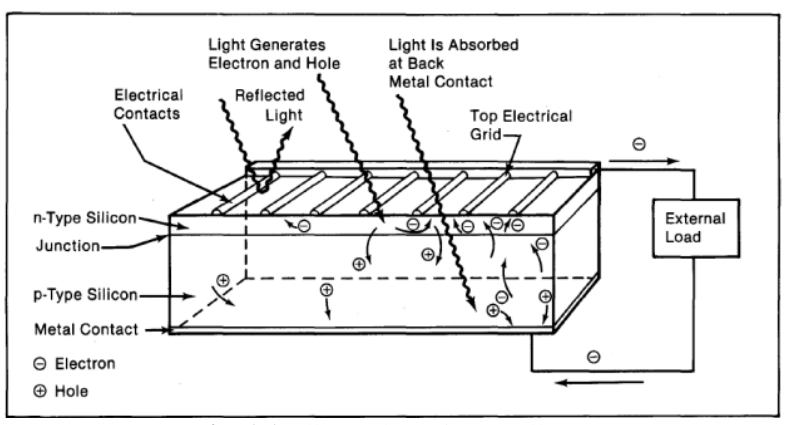

Fig. 1.1: Illustration of PV Cell [3].

In any PV system a single PV cell is not enough for generation of energy. The voltage required is met by series connection of these cells and parallel connection is made as per current requirement based on panel ratings. In this paper the data for the solar power plant is considered from the $50 \mathrm{KW}$ grid connected solar power plant placed at the roof top in my college. The real-time data of the plant data is graphically represented as shown in Fig 1.2.

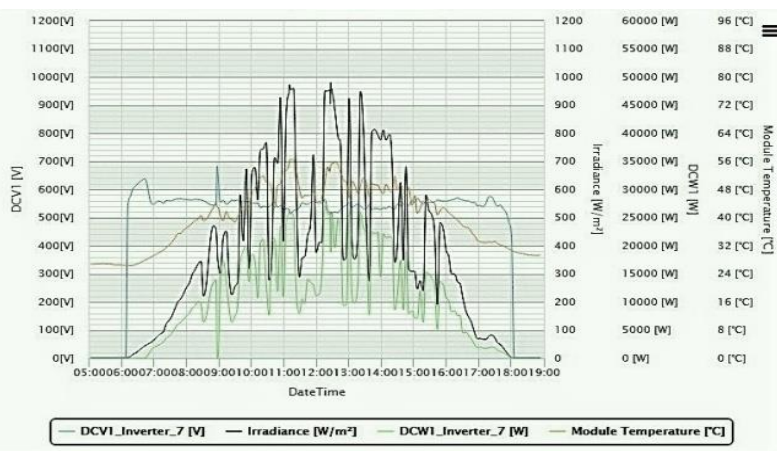

Fig. 1.2: Data Collected on 10-03-2017 at the Solar Inverter.

\subsection{Calculation of number of panels}

Here, the requirement is to obtain a voltage of $600 \mathrm{~V}$ D.C and a current of $83.33 \mathrm{~A}$ to meet $50 \mathrm{KW}$ load as per inverter rated DC voltage. Each panel is able to produce a open circuit voltage of $30.91 \mathrm{~V}$. So, 20 Panels are connected in series to form $600 \mathrm{~V}$ string. Each string is able to carry a current of $8.09 \mathrm{~A}$, to obtain desired current $10 \mathrm{such}$ Strings are connected in Parallel. Now, the total Number of panels required for the plant to operate at $50 \mathrm{KW}=20 * 10=200$.
Table 1.1: Name Plate of the Solar Panels Used in Our Vicinity

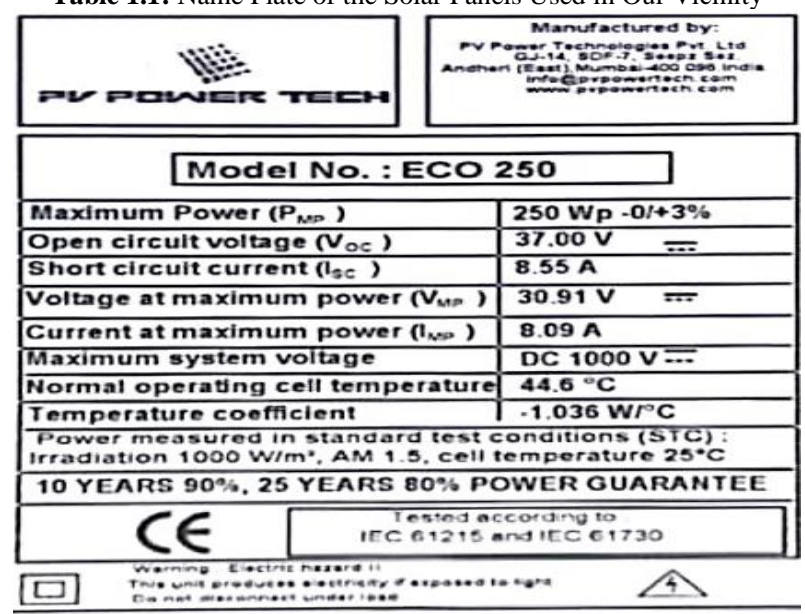

\subsection{Maximum power point tracking}

Though there are lot of advantages of Renewable energy resources, there are also some challenges like low conversion efficiency, high initial cost. Therefore, it is important to obtain the maximum possible power from the panels installed. It is needed to consider that there exists only one maximum power point because of varying climatic conditions and non-linear characteristics of solar panel as shown in Fig 1.3. Tracking that maximum point is a hectic task. There are so many methods proposed to find that maximum point [2]. In this paper $\mathrm{P} \& \mathrm{O}$ method is implemented.

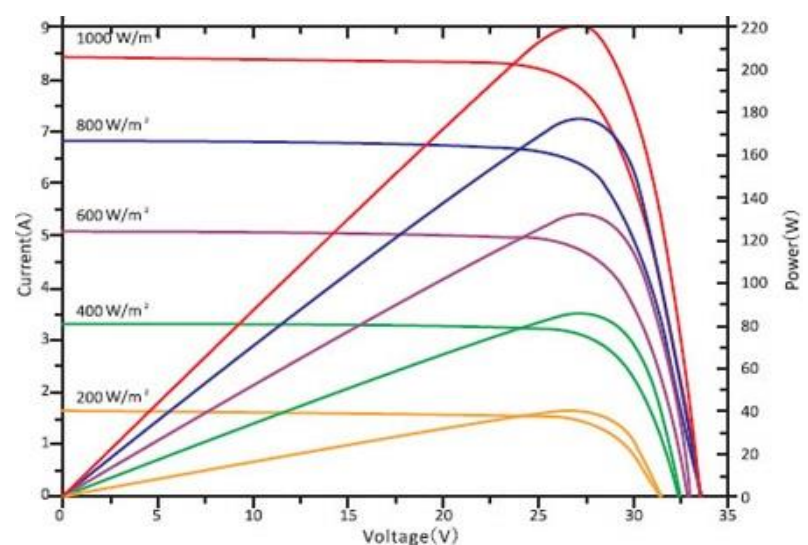

Fig 1.3: IV and PV Curves of Solar Panel as Per Datasheet.

In any MPPT it is required to maintain the DC bus voltage constant. In this paper it is $600 \mathrm{v}$. The values of voltage and current are to be measured at the PV side continuously and comparison is made within cycles i.e., present to previous cycles, decision will be taken to fix the maximum operating point. The operating point is changed by the controller with the changes in voltage and power correspondingly. Once the change in the direction is known, by varying controller at a constant rate the balance between faster response with less fluctuation in steady state is brought [2]. The flowchart for the above algorithm is as shown below Fig 1.4. 


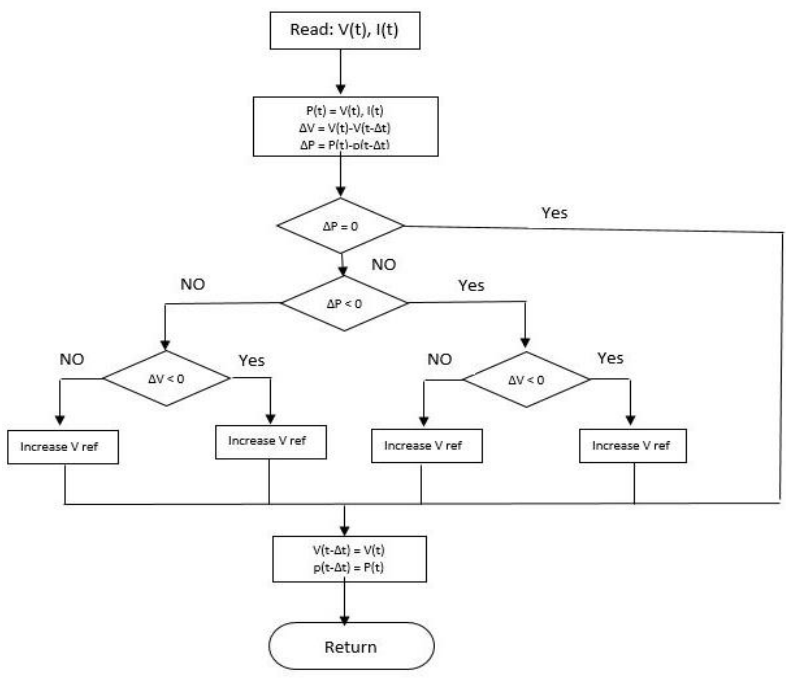

Fig 1.4: Flow Chart of Perturb and Observe Algorithm.

\section{Fuel cell system}

In future, fuel cells can be an attractive solution to vehicle drives and as an alternative source for generation of electrical energy. In any fuel cell chemical energy gets converted to electrical energy. Because of recent advancements, Proton exchange membrane fuel cells can be manufactured from the order of few milli-watts to kilowatts. These lead to wide range of applications. Proton exchange membrane fuel cells has gained much importance because of the low operation temperature, high power density and high energy conversion efficiency. Further there also have several issues to be noted [4]. In this paper a Fuel cell stack in MATLAB Simulink library is used. Here, it is considered that there is a constant temperature, supply of hydrogen and air. The power rating of the PEMFC is considered to be $50 \mathrm{KW}$.

\section{Control unit for the Micro grid}

Control plays a crucial role in the emerging technologies especially Micro grid as its failure will completely collapse the system. This system will obtain inputs from the renewable source side in the form of measured voltage and reference voltage. But the reference voltage will go on varying based on the variation of irradiance in case of solar power plant. Reference voltage will be calculated from the MPPT, as mentioned in section 1.2.2 the duty will be calculated
[11]. From that duty the reference voltage will be calculated and fed to the control unit. Similarly, the three phase voltages and currents near the load at A. C. side are measured at corresponding bus bars and will be fed to the control unit.

Now, in the control unit the three phase quantities are converted to direct and quadrature components by means of DQ or Park transformation. Similarly, in dc side the error will be calculated between the reference and measured value and will be fed through a PI controller to obtain direct and quadrature components in D.C. side in terms of current. Quadrature component in D.C will always be zero. These are sent through the current controller in which a feed forward loop is implemented so as to obtain converted Direct and Quadrature voltages which reflects the variations in both sides of the bus. Now, by applying Reverse Park transformation on the converted Direct and quadrature components along with phase initially obtained the reference for pulse generator can be obtained [5]. Finally, based on the reference signal generated the pulses for the inverter are produced.

\section{Passive filter design}

The Passive filters are designed based on the harmonic content present in the system. Here a shunt LC filter is designed. To design Capacitor, we must assume that it should be able to deliver reactive power which is at least $10 \%$ of Active Power Consumption. So, assuming a load of $100 \mathrm{KW}$, capacitor should be able to deliver $10 \mathrm{KVaR}$.

We have Reactive Power $\mathrm{Q}=\sqrt{3} * \mathrm{~V}_{\mathrm{L}} * \mathrm{I}_{\mathrm{L}} * \operatorname{Sin} \phi$.

Here $\mathrm{V}_{\mathrm{L}}=440 \mathrm{~V}$. Assuming $\phi=90^{\circ}, \mathrm{Iph}=22.72 \mathrm{~A}$.

Now Capacitive reactance $=11.1775 \Omega$

So, Capacitance $=284.777 \mu \mathrm{F}$

We have to design such that resonance should occur at PWM frequency of $1800 \mathrm{~Hz}$. Since resonating frequency $=1 /(2 * \Pi * \sqrt{ }(\mathrm{L} * \mathrm{C}))$ So, the Inductance $=27.453 \mu \mathrm{H}$.

Similarly, this filter has to be designed for dominant frequencies to reduce THD in the System.

\section{Simulation results}

Block diagram representation of the entire system is shown in the fig 1.5. below.

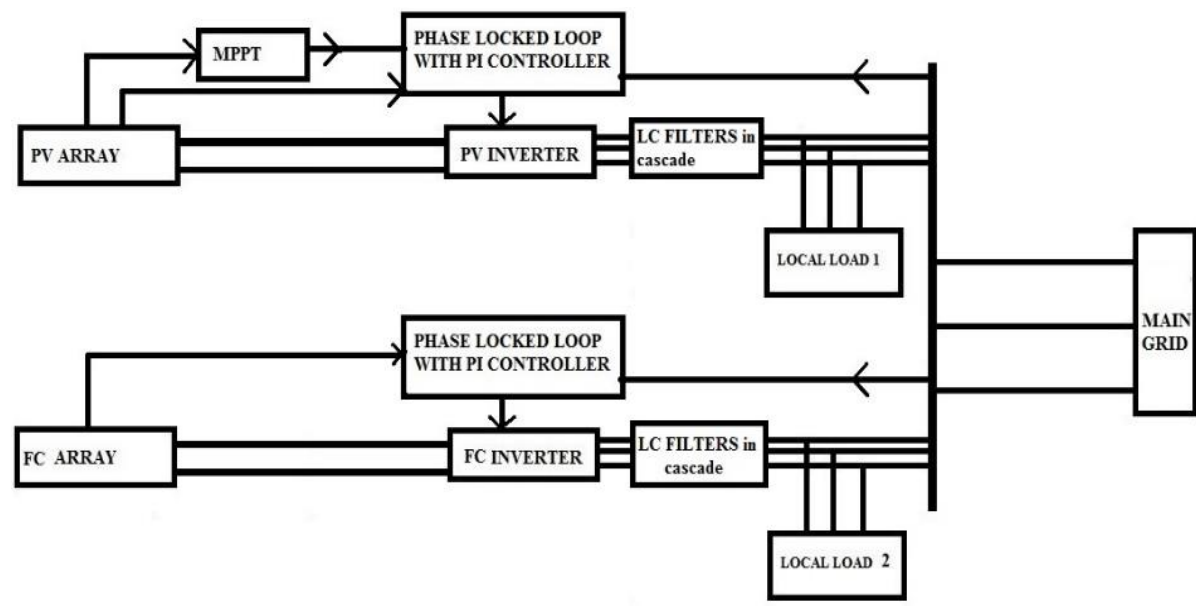

Fig 1.5: Block Diagram of the Entire System with Filter.

Table 1.2: THD Values at Various Locations with and without Filter

\begin{tabular}{|c|c|c|c|c|}
\hline LOCATION & $\begin{array}{l}\text { Without Filter } \\
\text { THD (Voltage) }\end{array}$ & THD (current) & $\begin{array}{l}\text { With Filter } \\
\text { THD (Voltage ) }\end{array}$ & THD (Current) \\
\hline At Renewable inverter side & $1.471 \%$ & $15.522 \%$ & $0.151 \%$ & $1.799 \%$ \\
\hline At Load point of common coupling & $1.472 \%$ & $15.3333 \%$ & $0.152 \%$ & $7.488 \%$ \\
\hline
\end{tabular}




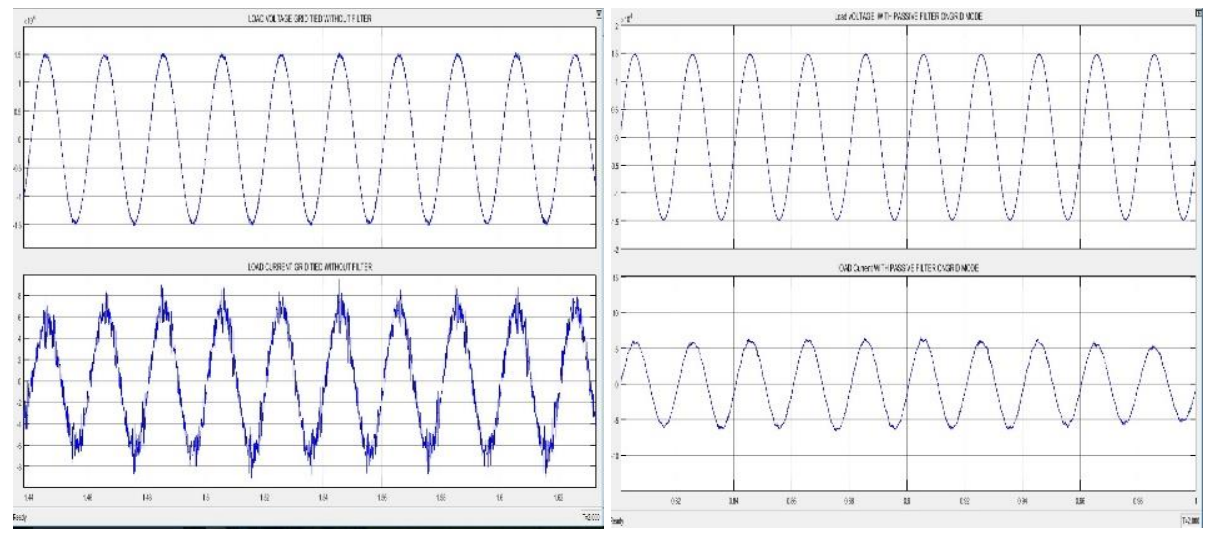

Fig 1.6: Voltage and Current Waveforms at Point of Common Coupling without and with Filter.

\section{Conclusion}

Micro grid technology is still evolving and research and developments are going on to address the issues like effective control, power quality and protection. This paper presents a basic idea about the Microgrid, Power quality in it and the control strategy of it. A renewable power of about $100 \mathrm{~kW}$ is connected to the conventional grid and the THD in the system is observed to be $7.48 \%$ for Variable irradiance solar input and a constant fuel cell, conventional input.

\section{References}

[1] Modeling and Digital Simulation of Solar pv Panel using MATLAB MBOUMBOUE Edouard, Donatin NJOMO, IJETAE (ISSN 22502459, ISO 9001:2008 Certified Journal, Volume 3, Issue 9, September 2013).

[2] "Comparative Analysis of MPPT Techniques for PV Applications", Macyor A. G. de Brito, Leonardo P. Sampio, Luigi G. Jr., Guilherme A. e Melo, Carlos A. Canesin, 2011 IEEE.

[3] Basic Photovoltaic Principles and Methods SERI/SP-290-1448 Solar Information Module 6213 Published February 1982.

[4] "Design of a Micro-Grid System in MATLAB/Simulink" by RajdeepChowdhury, TilakBoruah,IJIRSET

[5] Simulation of Synchronous Reference Frame PLL based Grid Connected Inverter for Photovoltaic Application by Mr. Shantanu Chatterjee and Dr. SaibalChatterjee in ICPDEN 2015.

[6] Investigations on Issues in Micro grids by Prerna Gaur and Sunita Singh, Journal of Clean Energy Technologies, Vol. 5, No. 1, January 2017.

[7] Research Report on Micro Grids Islanded Power Grids and Distributed Generation for Community, Commercial, and Institutional Applications Published 4Q 2009 by Pike research.

[8] "Control Scheme for Power Quality Improvement in Islanded Microgrid operation", N.S. Srivatchana, P. Rangarajan, S. Rajalakshmi, ScienceDirect.

[9] "A Study of Various Filters for Power Quality Improvement", DharmendraGour, DevendraDohare, AbhishekSaxena,IJAREEIE.

[10] PV power tech data sheet for silicon poly type ECO 250 type solar panel (www.pvpowertech.com).

[11] RamanaPilla and M.D.V. NookaRaju "Simulation of a Grid Connected Photovoltaic Array with Maximum Power Point Tracking," International Journal of Pure and Applied Mathematics, Vol.114, No.7, 2017, pp.217-226 